\title{
Infinity, Continuity, and Composition: The Contribution of G regory of Rimini
}

\author{
RICHARD CROSS \\ Oriel College, Oxford
}

Gregory of Rimini (1300-1358) occupies an important place in the fourteenth-century indivisibilist controversy, offering by far the most sophisticated accounts of both infinityand continuityto emerge from scholasticism. ${ }^{1}$ As is well known, Gregory holds that a continuum is composed of an actual infinity of parts. ${ }^{2}$ Less well known, however, are Gregory's motivationsfor accepting this view, and indeed how precisely he understandsit.

Gregory explicitly opposes two different but related views: that of the Aristotelians who claim that a continuum is composed of a potential infinity of divisible parts, and that of Henry of $\mathrm{Harclay}$ who claims that a continuum is composed of actually infinitely many indivisible points. As Gregory sees it, the views he opposes are united in their claim that, if a continuum is composed of actually infinitely many parts, then each part must be immediately adjacent to at least one and at most two other parts. Thus, as we shall see, $\mathrm{H}$ arclay accepts that a continuum is composed of actually infinitely many points, each of which is adjacent to at least one

I would like to thank Jeremy Catto, Chris Kraus, and Rowland Stout. Comments offered by two anonymous readers for M edieval Philosophy and Theology helped me in many ways in framing the final version of this essay.

1. I refer to Gregory's Sentence commentary [ = S], ed. A. Damasus Trapp et al., Spätmittelalter und Reformation: Texte und Untersuchungen, 6-(Berlin and New York: Walter de Gruyter, 1979-). On Gregory's life, see S, 1:XI-XVII. The Sentence commentary is based on lectures Gregory delivered in Paris during the academic year 1343-1344.

2. On this, see Anneliese Maier, Die Vorläufer Galileis im 14.Jahrhundert: Studien zur Naturphilosophie der Spätscholastik, Storia e L etteratura: Raccolta di Studi e Testi, 22 (Rome: Edizioni di Storia e Letteratura, 1949), pp. 172-73, 176-77; John E. Murdoch, "Infinity and Continuity," in The CambridgeH istory of Later M edieval Philosophy, ed. Norman Kretzmann, Anthony Kenny, and Jan Pinborg, (Cambrige: Cambriige University Press, 1982) pp. 572-73; J. M. M. H. Thijssen, "Roger Bacon (1214-1292/ 1297): A Neglected Source in the Medieval Continuum Debate," Archives internationales d'histoire des sciences 34 (1984): 25-34 (p. 31); Thijssen, "Het Continuum-Debat bij Gregorius van Rimini (1300-1358)," Algemeen N ederlands Tijdscrhift voor Wijsbegeerte 77 (1985) : 109-19; A. W. Moore, The Infinite, The Problems of Philosophy: Their Past and Their Present (London and New York: Routledge, 1990), pp. 51-54. 
other and at most two; while the Aristotelians accept that, since points cannot be immediately adjacent to each other, a continuum cannot be composed of infinitely many points. Gregory's major achievement is to refute this (mistaken) view. I discuss Gregory's replacement claim-that each of the (infinitely many) parts of a continuum is immediately adjacent to infinitely many parts-in section four. In sections one to three, I develop Gregory's argument in favor of his account of the composition of a continuum: (1) that it is false that a continuum is composed of points; (2) that it is false that there are such things as points at all; (3) that if a continuum is (as the Aristotelians hold) composed of a potential infinity of parts, then it must be composed of an actual infinity of parts. In section five, I show how Gregory develops an account of the mathematics of infinity that allows him to defend his theory of the composition of a continuum. In the final section, I show how he uses this account to deal explicitly with Henry of Harclay's version of the claim that each of the infinitely many component parts of a continuum must be immediately adjacent to at least one and at most two other such parts.

\title{
I. THE REJECTION OF HENRY OF HARCLAY'S INFINITIST INDIVISIBILISM
}

According to Henry of $\mathrm{H}$ arclay, a magnitude is composed of infinitely many indivisibles such that each one of these indivisibles touches at least one other, and at most two others. They do this by being in places that are immediately adjacent to each other. 3 Henry proposes a famous argument for his view: the omniscient God sees all the (infinitely many) points in a continuum, and thus sees point adjacent to point. The argument as usually discussed by thinkers of the fourteenth century (including Gregory of Rimini) is found reported in William of Alnwick. I quote it in full:

\begin{abstract}
God actually sees or knows the first beginning point of a line, and any other point which it is possible to pick out in the same line. Therefore, either [ $i$ ] God sees that, in between this beginning point of the line and any other point in the same line, a line can intervene, or [ii] not. If not [i.e., (ii)], then he sees point immediate to point, which is what we propose. If so [i.e. (i) ], then, since it is possible to assign points in the intermediate line, those points will not be seen by God, which is false.
\end{abstract}

3. On H arclay, see John E. Murdoch, "Henry of Harclay and the Infinite," in Studi sul xiv secolo in memoria di Anneliese Maier, ed. A. Maierù and A. Paravicini Bagliani, Raccolta di Studi e Testi, 151 (Rome: Storia e Letteratura, 1981). On the immediate adjacence of $\mathrm{H}$ arclay's infinite indivisibles, see "Henry of $\mathrm{H}$ arclay and the Infinite," p. 230; also Murdoch, "Superposition, Congruence and Continuity in the Middle Ages," in L'aventure de la science: M élanges Alexandre Koyrél, ed. I. Bernard Cohen and René Taton, H istoire de la pensée, 12 (Paris: Hermann, 1964), pp. 430-31; Murdoch, "Infinity and Continuity," p. 577 n.39. 
The consequence is clear, for according to what we have posited a line falls between the first point and any other point ( of the same line) seen by God, and consequently there is some midpoint between this point and any other point seen by God. Therefore this midpoint is not seen by God. 4

When dealing with the first disjunct, Henry presupposes two claims: ( 1 ) that the two points seen by God are such that God sees no further points between them; and (2) that any line contains points. Thus, H enry attempts to disprove the first disjunct by showing that accepting it entails-absurdly-that there will be points which God does not see.

Gregory responds explicitly to this argument. But he does so in ways which concede, counterfactually-for the sake of argument-that there could be such things as points. The response Gregory offers builds on an understanding of the actually infinite which Gregory constructs when developing his own account of the composition of a continuum. So I defer discussion of Gregory's explicit response to H enry's omniscience argument until the final section of this essay. As I show, Gregory's own discussion of the composition of a continuum is built around a very different understanding of infinity from that offered by $\mathrm{H}$ enry.

Gregory in fact consistently rejects the view that a magnitude could in any sense be composed of indivisible points. $5 \mathrm{He}$ understands such indivisibles to have zero extension. 6 If a magnitude were composed of point-like indivisibles, these indivisibles would be either finitely or infinitely many. The first of these options-composition from finitely many indivisibles-is rejected using standard arguments from the Aristotelian tradition. Gregory

4. William of Alnwick, Determination es [ = Det.] 2 (MS Vat. Palat. Lat. 1805, fol. $11^{r-v}$ ), quoted in Adam Wodeham, Tractatus del ndivisibilibus: A Critical Edition with Introduction, Translation, and Textual N otes, ed. Rega Wood, Synthese H istorical Library, 31 (Dordrect, Boston, and London: Kluwer Academic Publishers, 1988) , p. 289 n.2.

5. Gregory usually uses the term 'magnitudo' in this context, which he seems to use synonymously with the term 'continuum'. I shall follow his usage as far as reasonably practicable. Discussing passages where Gregory talks about magnitudes, I shall talk about magnitudes; and in passages where Gregory talks about continua, I shall likewise talk about continua. Gregory's usage here is not ideal because the medievals held that some continua lack quantitative extension-the motion of angels, for example, or matter as such. But if we keep this caveat in mind, I do not think we will be in much danger of being misled by Gregory's discussion.

6. S 1.35-6.1.1 ad $7(3: 223,11.27-29)$ : "In one way an indivisible . . . lacks any actually divided parts, or [parts] potential to division or distinction, as many imagine a point to be." Of course, on this definition, the sort of indivisibles Gregory is talking about could be macro-indivisibles of the sort proposed by Adam Wodeham (on this, see Norman Kretzmann, "Adam Wodeham's Anti-Aristotelian AntiAtomism," H istory of P hilosophy Q uarterly 1 [ 1984]: 381-98). But Gregor y consistently ascribes to the view he is rejecting the claim that the relevant sort of indivisible is a point, and his own account of the real divisibility of a continuum excludes his accepting anything like Wodeham's position here. So I take it that Gregory regards divisibility as a necessary feature of any quantity. 


\section{RICHARD CROSS}

divides the arguments into two groups: mathematical and physical. ${ }^{7} \mathrm{He}$ gives nine mathematical arguments (which I do not discuss here), all of which turn on absurd consequences which result in geometry if we suppose that a magnitude is composed of a finite number of indivisibles. 8

The physical arguments against composition from finitely many pointlike indivisibles derive more directly from Aristotle's Physics. The most interesting is the first: Aristotle's claim that two indivisibles-and presumably any finite number of indivisibles-would not occupy any greater space than just one. ${ }^{9}$ Underlying this is of course the view that an indivisible has zero extension.

Given this physical argument against the possibility of a magnitude's being composed of a finite number of indivisibles, Gregory's argument against the possibility of a magnitude's being composed of infinitely many point-like indivisibles is at first glance surprising. Gregory argues that infinitely many indivisibles would indeed compose a magnitude. But, he reasons, any magnitude so composed would be infinitely extended.10 There are at least two reasons why this conclusion is surprising. First, as we shall see below, Gregory is happy to claim that a magnitude is composed of infinitely many parts. But the element of surprise can be eliminated if we bear in mind that these parts are extended, such that smaller parts can be contained by larger parts. As Gregory notes: "Each [part], however small, includes infinitely many [ parts]."11 Gregory presumably supposes that un-

7. Gregory generally takes his arguments as equally pertinent to both mathematical and physical objects. (There is one notable exception to this, which I note in the next section.) The division of arguments into mathematical and physical does not signal their applicability to different sorts of object, but rather reflects merely the different natures of the premisses employed and conclusions reached.

8. S 2.2 .21 (4:279, 1. 1-p. 285, 1. 16). The fourth of these ( 5 2.2.2.1 [ 4:281, 1. 12-p. 283, 1. 14]) is discussed in detail in Thijssen, "H et Continuum-Debat," pp. 116-18. The two most well-known (Gregory's fourth and fifth [S 2.2.2.1 (4:281, 1. 12-p. 284, 1. 6) ]) are based on arguments taken from Duns Scotus: see his O rdinatio [ = 0] 2.2.2.5, nn.320-31 (Opera Omnia, ed. C. Balić et al. [Vatican City: Vatican Press, 1950- ], 7:292-98).

9. S 2.2.2.1 (4:285, 1. 18-p. 286, 1. 8); see Aristotle, Physics [= Ph.] 6.1 (231a29-b10); De Generatione et Corruptione [ = De Gen .] 1.2 (316a29-31). Two other of Gregory's arguments are straightfor wardly Aristotelian: S 2.2.2.1 (4:286, 1. 9-p. $288,1.5)$; see Aristotle, Ph. 6.2 (232a6-18). The remaining argument is an ingenious one relying on the reasonable presupposition that the physical process of rarefaction takes place without the generation of new matter. On this sort of view of rarefaction, the process could not involve the addition of new indivisibles. So the rarefaction of a substance composed of indivisibles would require either that each indivisible expands, or that each begins to occupy more than one space. Both of these are impossible: $S$ 2.2.2.1 (4:288, II. 6-14).

10. S 2.2.2.1 (4:278, II. 19-28). The argument is found in the indivisibilist William Crathorn, In Sententias 4 (MS Basel B.V.30, fol. 59). For the text, see Adam Wodeham, Tractatus de indivisibilibus [ = DI ], 24 n.33; also n.32.

11. S 1.35-6.1.1 ad 7 (3:224, II. 8-9; see also II. 5-7); I quote in section four below the full passage from which this important text is taken. 
extended, point-like indivisibles cannot be contained within each other in this sort of way-hence his conclusion that infinitely many such indivisibles yield an infinitely large magnitude.

Secondly, Gregory claims both that a magnitude composed of a finite number of indivisibles would have zero extension, and that a magnitude composed of infinitely many indivisibles would have infinite extension. Gregory's reason for claiming that a magnitude composed of infinitely many indivisibles would have infinite extension is that each numerically equal group of indivisibles is "equal in magnitude."12 But this cannot be correct, since it contradicts the supposition that an indivisible has zero extension. Whatever we make of Gregory's discussion of this point, the overall thrust of the discussion is obvious: it is not possible for a magnitude to be composed of point-like indivisibles.

\section{NON-ENTITISM AND THE REJECTION OF POINT-LIKE INDIVISIBLES}

In fact, like most nominalists, Gregory does not really think that there could be such things as point-like indivisibles at all. He thus accepts what has recently and helpfully been labeled "non-entitism": that point-like indivisibles do not exist, either as component parts of a magnitude or as the limits of a magnitude.13 The importance of non-entitism in Gregory's argument is two-fold. On the one hand, part of the motivation for accepting non-entitism is a desire to avoid some of the problems that arise from the assumption that points exist-in particular, Henry's claim that a continuum is composed of points. Thus, as we shall see in a moment, two of Gregory's arguments in favor of non-entitism expressly draw on the insight that, if indivisibles exist ( for example, at the limits of bodies), then bodies must be composed of such indivisibles. On the other hand, Gregory's non-entitism gives him a further reason for wanting to deny Henry's position. At one point, Gregory expressly replies to Henry's position by invoking his nonentitism. There are no such things as points at all; a fortiori, then, there are no points in a line. 14

12. S 2.2.2.1 (4:278, II. 27-28). A related claim can be found in Robert Grosseteste. According to Grosseteste, a finite number of indivisibles does not yield a magnitude, but an infinite number will: see Grosseteste, De L uce seu Inchoatione Formarum (Die philosophischen Werke des Robert Grosseteste, ed. L. Baur, Beiträge zur Geschichte der Philosophie des Mittelalters, 9 [M ünster: Aschendorff, 1912]), pp. 53-54 (for the first claim) and p. 52 (for the second). Of course, Grosseteste is not committed to Gregory's puzzling claim that an infinite number of point-like indivisibles yields an infinite magnitude.

13. See Wood's edition of Wodeham, DI, p. 11.

14. S 2.2.2.1 (4:291, II. 28-30). 


\section{RICHARD CROSS}

In this section, I will look at some of Gregory's (generally conventional) arguments for accepting non-entitism. To understand his position, we need to understand a distinction that he consistently draws between mathematical objects and physical objects. Mathematical objects are imaginary. We can discuss one- and two-dimensional objects so long as we keep in mind that these are themselves imaginary. 15 Physical objects are real; but there are no real distinctions between their different dimensions. The length, depth, and height of a body, for example, are not real components of that body. 16

There are important analogies between Gregory's treatments of mathematical objects and physical objects. As we have seen, he uses both mathematical and physical arguments to show that neither mathematical nor physical magnitudes can be composed of point-like indivisibles. But there are some disanalogies, too. Geometers need to be able to talk about limits in terms of (imaginary) points and surfaces; physicists do not. Imaginary mathematical objects include imaginar y indivisibles at their limits; real physical objects do not include indivisibles, real or imaginary, at their limits. 17

According to Gregory, it is easy enough to show that contradictions occur if we suppose that a physical body could somehow include indivisibles as real things. Gregory initially proposes three mathematical arguments and two physical arguments against the real existence of indivisibles. The two physical arguments are straightfor wardly Aristotelian. (1) According to Aristotle, an indivisible cannot move, since every moving object first traverses a distance less than or equal to itself. An indivisible would first traverse a distance equal to itself; hence the magnitude over which it moved would itself be composed of point-like indivisibles- which is false.18 (2) If the limits of a body are indivisible, then a body has a part (that is, its edge) according to which it is first moved-which is impossible. ${ }^{19}$ Similarly, if the limits of a body are indivisible, then there is some first part of the space over which the body is moved-which is likewise impossible. 20 Aristotle's reason

15. S 2.2.2.1 (4:323, II. 17-26).

16. S 2.2.2.1 (4:324, II. 6-9). Gregory is not denying that bodies are really extended. $\mathrm{H}$ is claim is that every physical body-all real extension-is necessarily three-dimensional.

17. Curiously, Gregory does not believe the mathematical arguments to be effective against the postulation of imaginary indivisibles in geometry; perhaps, like Ockham, he regards mathematical theorems as conditionals, and some of them as counterfactual conditionals: for example, if indivisibles existed, then such and such a theorem would be factually true. For a discussion of Ockham, see Murdoch, "Ockham and the Logic of Infinity and Continuity," in Infinity and Continuity in Ancient and M edieval Thought, ed. Norman Kretzmann (Ithaca and London: Cornell University Press, 1982), p. 178.

18. S 2.2.2.1 (4:317, 11. 3-9); see Aristotle, Ph. 6.10 (24a6-14).

19. S 2.2.2.1 (4:318, 11. 30-4); see Aristotle, Ph. 6.5 (236a10-15).

20. S 2.2.2.1 (4:319, 11. 1-10); see Aristotle, Ph. 6.5 (236a33-34); 6.6 (237a34-35). 
for the impossibility of the second case here is that the existence of a first part of a magnitude entails ( falsely) that the whole magnitude is composed of indivisible parts. 21 Presumably, he could argue similarly in the first case.

Secondly, the mathematical arguments. (1) If a magnitude is bounded by points, then clearly some parts of the magnitude lack points. So these parts cannot be bounded by points, assuming the limits of a magnitude to be intrinsic to it.22 (2) Suppose every magnitude includes points. Let $A$ and $B$ be two superposed magnitudes. God destroys all of A except for any points $A$ includes. Either ( $i$ ) the points remaining occupy all of the space previously occupied by $A$, or (ii) they do not. If (i), then the points remaining are immediate to correlative points on $B$, which violates the Aristotelian stipulation that points cannot be immediate to each other. If (ii), then A includes some parts which do not themselves include points-which is Gregory's contention.23 (3) It makes no sense to speak of a point limiting a magnitude such that the point somehow stops the magnitude from getting any bigger. Therefore, there is no need to posit the existence of points. 24

Gregory gives a series of objections to his non-entitism. The most interesting is the fifth, an objection that has been discussed recently (by a different set of thinkers) in the pages of this journal.25 The objection runs as follows. A sphere touches a plane at a point. If points do not exist, then

21. To be precise, the magnitude Aristotle is interested in the crucial Ph. 6.5 (236a-34) is time. Gregory takes Aristotle's composition claim to be equally applicable in the case of a spatial magnitude.

22. S 2.2.2.1 (4:313, 11. 18-23). The argument is clearly specious. The opponent of non-entitism could plausibly claim that the proposed scenario simply begs the question. Necessarily, as soon as we have a discrete magnitude, we have the intrinsic indivisibles bounding it. We cannot have the magnitude without its boundaries. Someone defending this sort of view would certainly want to claim that a magnitude cannot be chopped off immediately before its boundaries, since there is no part of the magnitude which is immediate to its boundaries. Gregory cites William of Alnwick to this effect: the existence of a line, according to William, is sufficient for the existence of a limiting point (S 2.2.2.1 [4:315, 11. 18-21], citing William, Det. 2 [MS Vat. Palat. Lat. 1805, fol. 14v]. The text can be found in Gregory, S, 4:315 n.4). Gregory replies that there is no sense in which the existence of a line is sufficient for the existence of a point, since there is no sort of cause which the line could be with respect to the point (S 2.2.2.1 [4:315, 11 . 23-25]). Obviously, Gregory presupposes that there could not be any relevant non-causal sort of sufficiency here, though I do not see why he should suppose this.

23. $S$ 2.2.2.1 (4:314, 11. 6-22). The question of superposed magnitudes is discussed in John E. Murdoch, "Superposition, Congruence and Continuity."

24. S 2.2.2.1 (4:314, 1. 32-p. 315, 1. 15).

25. On the objection as found in Ockham, Wodeham, and Buridan, see the detailed discussion in Jack Zupko, "Nominalism Meets Indivisibilism," M edieval Philosophy and Theology 3 (1993): 158-85. Rega Wood describes the objection as the most interesting of the fourteenth-century objections to entitism: see her edition of Wodeham's DI, p. 15. 
the sphere could not touch the plane-which is absurd.26 Gregory's reply is a standard one developed earlier by the non-entitist Adam Wodeham. ${ }^{27}$ Gregory first of all rejects the appealing reply that spheres and planes are merely imaginary, mathematical, objects. He replies instead that, if we understand 'touch' to obtain only when there is nothing between two bodies, then the sphere does not touch the plane; whereas if we understand 'touch' to obtain when two bodies cannot be closer, then the sphere does indeed touch the plane. 28

There is nothing especially startling about Gregory's non-entitist arguments. Although almost universally rejected in the thirteenth century, 29 non-entitism was the majority view in the fourteenth century. Its importance here, of course, is that it gives Gregory another set of reasons for wanting to reject Henry of Harclay's indivisibilism. In the next two sections, I look at Gregory's divisibilist proposals for the composition of a continuum.

\section{THE COMPOSITION OF A CONTINUUM}

As we have seen, Gregory denies that magnitude is composed of point-like indivisibles, whether finite or infinite in number. Given this, Gregory infers instead that a magnitude is composed of parts that are themselves magnitudes. 30 The sort of extended parts Gregory has in mind are proportional parts: the sort of parts that can be obtained by dividing the whole and each of its parts into halves, or thirds, and so on. 31 Clearly, if these parts are to count as components of a continuum, there must be a sense in which the parts exist. Gregory makes use of the commonplace distinction between actual and potential parts. As Gregory understands the distinction, actual parts are discrete items. Matter and form count as actual parts. 32 But the extended parts of a magnitude are not like this. Thus, "none [ of the parts] is in itself one 'this something' precise and distinct from another." 33 Never-

26. S 2.2.2.1 (4:321, 11. 19-24). p. 173.

27. On the reply in Wodeham, see Zupko, "Nominalism Meets Indivisibilism,"

28. S 2.2.2.1 (4:329, 11. 15-34).

29. The only exception to this that I know of is Peter John Olivi: see his Quaestiones in Secundum Librum Sententiarum 2.31 (ed. Bernardus Jansen, 3 vols., Biblioteca Franciscana Medii Aevi, 4-6 [Quaracchi: Collegium S. Bonaventurae, 1922-1926], 1:554, 557).

30. S 2.2.2.1 (4:288, 11. 17-19).

31. S 2.2.2.1 (4:295, 11. 10-13). It is important to understand that each of the parts of a magnitude will be so divided. The claim thus is not just that a magnitude contains extended parts, but that it is composed of them. On this, see below, n.51.

32. $S$ 1.24.1.1 ad $2(3: 18,11.24-5,27-28)$.

33. S 1.24.1.1 ad 2 (3:19, 11. 2-3); see also S 2.2.2.1 (4:296, 11. 1-4). 
theless, the parts "actually exist by the actuality of presence." 34 They are real, but remain parts of a discrete magnitude. 35

Given that these parts are not themselves discrete items, we might be inclined to think that they cannot be in any sense counted. But Gregory disagrees. Even though the parts are not physically divided from each other or the whole which they compose, we can divide them conceptually. When discussing whether or not the division of a continuum can be completed ( $a$ discussion to which I return below), Gregory notes that the relevant division is not "division of real separation into discrete things" 36 but rather "division which is made by the signification of the distinguishing intellect, which [division] is compatible with real continuity in the continuum thus divided." 37 We can thus count these potential parts by imagining divisions between them. And the parts thus counted are, according to Gregory, "actually many." 38 To support this conclusion, Gregory offers three arguments. 39 (1) The potential parts of a magnitude are spatially distant from each other. And spatially distant potential parts are numerically many. (2) The potential parts of a magnitude differ in extension. But differently sized parts are numerically many. (3) A magnitude can be physically divided in at least some of the ways in which it can be conceptually divided. And parts which can be physically divided from each other are numerically many.

34. S 1.24.1.1 ad 2 (3:18). For a similar distinction, see Scotus, 0 1.17.2.1, nn.232-33 (5:251-52).

35. O ckham believes that the component parts of a continuum are actual, not potential, parts. I am not sure, however, that O ckham's point is much different from Gregory's. O ckham does not share Gregory's tight restriction on the criteria for actual existence (that is, physical discreteness), and instead explicitly dissociates the kind of existence something has (actual versus potential) from the sort of relations which it has to other things. Thus, for Ockham, being a continuous part of a whole continuum does not in any way prevent the part from having actual existence. For the whole discussion, see Ockham, Expositio in libros Physicorum Aristotelis [ = Exp. Ph.] 1.11.1 (Opera Philosophica, ed. Iuvenalis Lalor et al., 6 vols. [St Bonaventure, N.Y.: St Bonaventure University, 1967-1985], 4:110, 11. 45-51), usefully discussed in John E. Murdoch, "Ockham and the Logic of Infinity and Continuity," pp. 186-87. But for a part to have this sort of actual existence seems to be exactly what Gregory has in mind when he claims that a part has potential existence. Gregory's account of the matter is far more in line with the standard scholastic reading of the distinction.

36. S $1.35-6.1 .1$ ad $7(3: 223,1.18)$.

37. S $1.35-6.1 .1$ ad $7(3: 223,11.19-20)$.

38. S 2.2.2.1 (4:295, 1. 6). By talking of a conceptual division, Gregory is not trying to make a contrast with some sort of actual division. When commenting on God's division of a continuum into all its (potential) parts, Gregory notes: "I say that in God's conception, the continuum is totally actually divided into parts": $S$ 1.35-6.1.1 ad 7 (3:224, 11. 10-11). (I discuss this important passage in greater detail below.) So perhaps we can talk of a continuum being actually (conceptually) divided-as opposed to actually physically divided.

39. S 2.2.2.1 (4:295, 11. 15-35). 
Presumably Gregory intends the conclusion here to be understood of potential parts prior to physical division.

To understand these inferences, it is important to keep in mind that Gregory believes conceptual divisibility to be in some sense sufficient for countability. The first two of the three arguments just given specify conditions under which conceptual divisibility is possible: we can conceptually divide anything which is extended (argument one), and we can conceptually divide anything whose parts are different sizes (argument two). These claims seem eminently reasonable. The third argument, however, appears to be question-begging. It is by no means obvious that the mere possibility of physical division is sufficient for countability.

Gregory's conclusion is that a magnitude is composed of actually many extended potential parts. Can we say how many such parts there are? Gregory believes that his method of proportional division will yield actually infinitely many parts. This conclusion marks a large and striking move away from standard Aristotelian sorts of divisibilism. According to Aristotle, there is a potential infinity of parts in a magnitude. 40 Aristotle is supposing that the division of a magnitude is a process-however much we divide a magnitude, we can al ways divide it further. The process cannot be completed, and a magnitude thus cannot be composed of an actual infinity of parts: "It is plain that everything continuous is divisible into divisibles that are infinitely divisible." 41 Underlying Aristotle's claims about the division of a magnitude and the potential infinity of its parts are worries about the adjacence of points. Suppose counterfactually that a magnitude could be completely divided into all its parts. These parts, according to Aristotle, would be indivisible points. 42 But one of Aristotle's reasons for denying composition from points is the impossibility of points being immediately adjacent to each other: "If [a continuum] were divisible into indivisibles, we should have an indivisible in contact with an indivisible."43 So a magnitude, according to Aristotle, cannot be composed of an actual infinity of parts. (As we shall see below, Gregory's account entails denying the Aristotelians' adjacence claim - a claim that, as we have seen, they share with the indivisibilist Henry of Harclay. I deal with Gregory's replacement claim in the next section.)

Writers of the fourteenth century tended to replace Aristotle's distinction between the potential infinite and the actual infinite with a more rigorous distinction between the syncategorematically infinite and the categorematically infinite. Gregory notes that there are different ways of presenting this distinction. As he understands it, the syncategorematically infinite is such that, for any finite number, there exists something greater

40. Ph. 3.7 (207b12-13).

41. Ph. $6.1\left(231^{\mathrm{b}} 15-16\right)$.

42. See De Gen. 1.2 (316a23-25, 29-30).

43. Ph. 6.1 (231b16-17). For the impossibility of adjacent indivisibles, see Ph. 6.1 (231a21-31). 
than that number; the categorematically infinite is such that there exists something greater than any finite number. 44 As Gregory notes, something can be syncategorematically infinite without being categorematically infinite. For example, suppose the world is everlasting. In that case, it is true to claim that "infinite human beings will be past," so long as we understand 'infinite' here syncategorematically: there is no limit to the number of human beings who will live and die. But the proposition is false if 'infinite' is understood categorematically: there never will be a time when infinitely many human beings will have lived and died. 45

O ckham uses this distinction to talk about the potential infinity of parts in a continuum. $\mathrm{Ockham}$ argues that there are syncategorematically infinitely many parts in a continuum - for any finite number of them, there are always more-but not categorematically infinitely many-the process of division can never be completed. 46 So, just as in Aristotle's potential infinity, the categorematically infinite in O ckham is conceived in process-like ways. Gregory agrees with 0 ckham that there are syncategorematically infinitely many parts in a magnitude. Each part of a magnitude itself has further parts. So for any finite number of parts, there are always more, since each of these parts itself has parts. 47

There is nothing controversial about Gregory's account thus far. $\mathrm{H}$ is next move, however, is surprising. He argues that there are categorematically infinitely many parts in a magnitude, and that the categorematic infinity of the parts is entailed by there being syncategorematically infinitely many parts in a magnitude. Gregory offers four arguments to show this. Two of them are worth considering in some detail.

(1) To claim that a magnitude has infinitely many parts syncategorematically is to claim that for any finite number $n$ of the parts of the magnitude, the number of the magnitude's parts is greater than n. Gregory, as we have seen, argues for the infinity of parts syncategorematically by appealing to the actual (conceptual) divisibility 48 of a magnitude. Thus, any

44. S 2.2.2.1 (4:294, II. 10-16). On the distinction between categorematic and syncategorematic words, see Norman Kretzmann, "Syncategoremata, Sophismata, Exponibilia," in The Cambridge $\mathrm{H}$ istory of Later M edieval Philosophy, pp. 211-45. On categorematic and syncategorematic uses of 'infinite,' see Kretzmann, William of Sherwood's Treatise on Syn categorematic Words (Minneapolis: U niversity of Minnesota Press, 1968), pp. 41-43. Roughly, to use 'infinite' syncategorematically is to use it as a quantifier. Thus if we talk about-say- "infinitely many parts," we are refer ring to the parts, and noting that the parts are such that, for however many parts we have, we can always take more of them. To use 'infinite' categorematically is to refer to an infinite number: hence, a number "greater than any finite number."

45. S 2.2.2.1 (4:294, II. 30-35).

46. Exp. Ph. 3.13 .9 (4:555, II. 14-18); Exp. Ph. 6.13 .6 (5:562, II. 1-31, 1.47-p. 563, 1. 51); see Murdoch, "Ockham and the Logic of Infinity and Continuity," p. 189.

47. S 2.2.2.1 (4:296, II. 8-12).

48. For "actual (conceptual) divisibility," see n.38 above. 
extended part of a magnitude itself has extended parts. But Gregory believes this to entail that the totality of the magnitude's parts is greater than any finite number - that is, that the totality of parts is categorematically infinite. Gregory claims that, if the totality of parts were not infinite in this way, then we would (absurdly) have "to give a maximum to the number of parts." 49

(2) The totality of parts in a magnitude is ( $\mathrm{i}$ ) more than one, and (ii) not finite. So the totality of parts in a magnitude is categorematically infinite. Suppose the conclusion is false, and that the totality of parts is not categorematically infinite. Gregory claims that, on this supposition, the totality of parts would have to be finite, and hence that some of the parts would have to be indivisibles. Gregory, as examined in the first section of this article, is convinced that there cannot be such parts in a magnitude. $\mathrm{H}$ ence the totality of parts in a magnitude is categorematically infinite. 50

Both arguments rely on our being able to talk meaningfully of a totality of parts. And this, I think, makes it clear that Gregory is not thinking of the infinite in terms of any process. Aristotle and Ockham, after all, want to deny that the process of marking out parts by division could ever be completed-and hence, presumably, they would be unhappy with any talk of a totality of parts. Gregor y too denies the inference from the syncategorematically infinite to the categorematically infinite in the case of processes. Thus, Gregory's example of a case where the inference from syncategorematic to categorematic infinity is unsound, as we have seen, is a process: the gradual increase in the number of human beings. In the case of the components of a magnitude, however, Gregory imagines the parts as already given: hence his claim that there is a totality of parts. I imagine that our willingness to accept Gregory'sinference from the syncategorematically infinite to the categorematically infinite will depend precisely on our acceptance of its most controversial premise-namely that there is a totality of parts at all. In the next section, I look at Gregory's understanding of this controversial premise.

\section{THE TOTALITY OF PARTS AND THE PROBLEM OF ADJACENCE}

The claim that, if a continuum is composed of an actual infinity of parts, then it will be composed of parts, each of which isimmediately adjacent to at least one and at most two others, is central to both the Aristotelian and $\mathrm{H}$ arclayan

49. S 2.2.2.1 (4:296, II. 17-25). Of course, given that the parts are all extended, it will follow that totality of the parts of any parts of a magnitude is categorematically infinite.

50. S 2.2.2.1 (4:296, 1. 26-297, 1. 3). 
views which Gregor y rejects. In this section, I want to show how Gregory sets about denying this ( false) claim accepted by Aristotelians and indivisibilists alike. To understand Gregory's motivations, we need to keep in mind the overall shape of his argument thus far. Given that indivisibilism is false, and that, in the case of the parts of a continuum, we can reasonably argue from the syncategorematically infinite to the categorematically infinite, Gregory is committed to composition from infinitely many parts. $\mathrm{H}$ is strategy for dealing with the adjacence problem is ingenious: each part is immediately adjacent to infinitely many other parts. Gregory defends this claim by arguing that the infinitely many extended parts of a continuum are overlapping, in the sense that each contains other parts. Before I examine Gregory's treatment of the adjacence problem, I will discuss his crucially important claim that the infinitely many parts of a continuum all contain other parts. This will allow us to see clearly how Gregory understands talk of a totality of parts. We have already seen the basic claim; all the parts contain other parts because every part can be divided into proportional parts.

The claim that the infinitely many parts of a continuum all contain other parts is, of course, equivalent to Gregory's claim that they are all extended. It would be easy to misunderstand this position. Suppose with Gregory that a magnitude were completely (conceptually) divided into all its component parts. On the face of it, it looks as though these parts cann ot be extended, since by definition extended parts can always be further divided. And we might be tempted to think that it cannot be the case both that the division of a magnitude is completed and that there is still some magnitude "left over." As Gregory describes the division, however, it is the case both that the division is completed and that there is some magnitude left over. But thinking about Gregory's position in this way fails to grasp fully the nature of his insight. The point of the objection I have just given is that the last level of a completed division of a continuum should include infinitely many indivisibles. But Gregory does not need to accept this. Gregory's claim is that we can divide a continuum into proportional parts infinitely many times, but that none of these divisions will result in a level which contains infinitely many equal parts (or, for that matter, point-like indivisibles). The parts, on Gregory's account, all contain other parts: so as long as there are infinitely many levels of ever smaller proportional parts, there can be infinitely many proportional parts none of which is a point-like indivisible. Given that the division occurs "all over," Gregory's overlapping parts allow him to accept that a continuum is composed of the totality of its infinitely many proportional parts. 51

51. Clearly, on the account Gregory is proposing, the number of parts is countably infinite: each part can be paired off with a natural number. ( $O n$ this, see also n.74 below.)

We could, of course, accept the (failed) objection to Gregory's view, just outlined, without believing there to be a parallel objection to the claim that a continuum could contain infinitely many extended parts. Suppose we divide a 
O ne important passage summarizes all this:

\begin{abstract}
And just as every continuum in fact has infinitely many potential parts, and each [ part of it], however small, includes infinitely many [parts] (and no part can be understood to be indivisible; nor is there a potential infinity of such [indivisible] parts), so I say that in God's conception, the continuum is totally actually divided into parts, of which each is also totally actually divided, and includes infinitely many actually divided [parts].52
\end{abstract}

Gregory's talk about God's understanding of these matters makes it clear that he is thinking not of a process of division, and of a potential infinity of parts, but of a completed division, and of an actual infinity of parts. God's knowledge of these matters cannot be process-like, or temporally extended. The passage gives Gregory's solution to Henry's worry that, if God cannot know the infinitely many potential points on a line, then divine omniscience is compromised. According to Gregory, God can know all the infinitely many possible ways in which a continuum can be divided up. This knowledge, according to Gregory, does not require that there be infinitely many points on a line. More importantly, however, it does not require that God know extended parts adjacent to at least one and at most two other parts. In Gregory's account, a line is not composed of such adjacent parts, but of extended parts, each of which includes infinitely many smaller parts. I will return to Gregory's response to Henry in the final section of this essay. As we shall see there, Gregory's responses all make use of Gregory's insight that knowing all the parts of a continuum does not entail knowing parts adjacent to at least one and at most two others. 53

Given that the parts all contain other parts, in what sense can the division, as Gregory describes it, be completed? After all, the parts resultant from the division all themselves include further parts. Gregory deals with this by laying out some careful definitions of 'divisible' and 'indivisible'. As we shall see, Gregory's definitions allow him to claim consistently both that the division of a continuum can be completed, and that each part contains infinitely many smaller parts. The definitions come from an important discussion in which Gregory attempts to describe just in what way we should

continuum into ever smaller intervals approaching a limit. Clearly, however much we divide the continuum, there will al ways be something left over - an ever smaller inter val approaching the limit ( see for example, Ockham, Exp. Ph. 3.13.9 [ 4:555, II. 26-30] for just this sort of claim). But Gregory's proposal is much stronger than this: the divisions occur "all over," such that a continuum is composed of the totality of its parts.

52. S 1.35-6.1.1. ad 7 (3:224, II. 7-12); see also S 2.2.2.1 (4:296, II. 8-12), where Gregory claims that each part of a magnitude has parts.

53. Gregory's insight here is fundamentally one about the nature of an infinite multitude. But it also tells us something about his view of God's knowledge. God's knowledge, rather like the infinitely many parts of a continuum, cannot be listed. 
regard the completed (conceptual) division of a continuum. The discussion forms an attempt to respond to the standard divisibilist claim-as found in Peter Aureol-that it is "impossible for the division of a continuum to be totally exhausted."54 The motivation for this divisibilist claim is that the completion of the process of division would result in indivisibles - points - and (as we have seen) divisibilists claim that points could not possibly form the component parts of an extended magnitude.

Since Gregory accepts the existence of an actual infinity of parts in a continuum, he also accepts that the division of a continuum can in principle be completed. (I have al ready examined Gregory's claim that we should think of all the parts of a continuum as somehow "already there.") But he further claims that the parts resultant from the division are extended. In the following passage Gregory tries to distinguish a sense of indivisible which will allow for a completed division without invoking point-like indivisibles. The sense replaces the (irrelevant) standard definition, a thing which "lacks parts":55

In another way something can be said to be indivisible on the grounds that, even though it has parts in it, each [part] is actually divided from any other, such that [ the thing] is not divisible in any way, or [divisible] according to anything belonging to it that is not actually divided in that way. 56

It is this sense of 'indivisible,' according to Gregory, that is the sense relevant in the case of the completed division of a continuum, yielding parts that can be no further divided.57 Indivisibles in this sense are extended magnitudes-magnitudes that contain parts. These indivisible magnitudes contain parts that are actually divided. The point is that a magnitude is indivisible if it cannot be further divided-if it is divided up in every possible way. The indivisibles here are not the component parts of a magnitude but the magnitude itself, seen as composed of the totality of all its (infinitely many) parts. On this definition of 'indivisible,' Gregory can consistently claim both that the division of a continuum can be completed (against Aureol and the standard divisibilist view) and that the parts resultant from the division fail to be points. 58

54. S 1.35-6.1.1 ad 7 (3:223, II. 17-18). Gregory's professed opponent here is Peter Aureol: see his Commentaria in libros Sententiarum 1.35.2.1 ([Rome, 1596], $\left.772^{\mathrm{b} B C}\right)$. But the claim is a standard divisibilist one.

55. For this rejected definition, see above, n.6.

56. S 1.35-6.1.1 ad 7 (3:223, 11. 30-33).

57. S $1.35-6.1 .1$ ad $7(3: 223,1.36-224,1.1)$.

58. Modern commentators on Gregory tend to ascribe to him the view that a continuum is composed of infinitely many infinitesimal parts: see Maier, Die Vorläufer Galileis, pp. 172-73. Maier's admittedly tentative interpretation is followed by Thijssen, "Roger Bacon," p. 31; "H et Continuum-Debat," pp. 112-13; and Moore, 
A magnitude, then, is indivisible if it is actually (conceptually) divided into all its possible parts. Gregory redefines 'divisible' accordingly:

Something can be called divisible in two ways: in one way, since it has parts actually or potentially divided; in another way, since it has parts not actually divided. 59

Gregory claims that a continuum divided into all its parts is divisible in the first of these two senses: it is divisible in the sense of having parts which are actually (conceptually) divided from each other.60 Taking the two definitions together, Gregory holds that a continuum is indivisible not in the sense that it cannot be divided, but in the sense that it cannot be further divided; and a continuum is divisible in the sense that it has actually (conceptually) divided parts.

These senses of 'divisible' and 'indivisible' again make it clear that Gregory is not thinking of division as some kind of physical process. The crucial claim is that God can see right through the actually (conceptually) divided magnitude. This is why Gregory need not be troubled by the adjacence claims made by Aristotelians and indivisibilists alike. Gregory defends his position in response to an objection by an other wise unidentified "H ibernicus." According to this opponent, "It is impossible to imagine that some multitude is immediately joined, or contiguous, to something, unless one part of it is immediately joined." 61 On this view, a body $b$ can touch another one $b_{1}$ only if exactly one part of $b$ touches $b_{1}$. ('Touch' here is to be understood in the in the sense of there being nothing between the two bodies, as Hibernicus is thinking of two plane surfaces.) Clearly, the argument is equally applicable to the problem of the adjacence of the actual parts of a continuum.

Gregory's reply makes it clear where Hibernicus is going wrong:

I say that if this is impossible for someone, this is because he imagines a definite number of parts, and that one of them is the last. Someone who understands, however (as is true), that there are infinite parts, will

The Infinite, p. 54. This reading seems, in the light of the texts we have just been considering, patently false. Gregory unequivocally claims that the parts resultant from the division are extended, and that they all contain smaller parts. None of these parts is an (indivisible) infinitesimal.

I think that there are reasons for the curious reading of Gregory suggested by Maier: in particular, the prima facie difficulty of understanding how it can be both that the division of a continuum can be completed and that each divided part contains infinitely many smaller parts. I have tried to show above how I think we should understand Gregory's claim.

59. S 1.35-6.1.1 ad 7 (3:223 11. 34-5).

60. S 1.35-6.1.1 ad 7 (3:224 11. 4-5).

61. S 2.2.2.1 (4:299, 11. 23-5); for the whole objection, see S 2.2.2.1 (4:299, 1. 14-300, 1. 11). 
well understand that none is immediate to [ the body the multitude is joined to]. 62

How should we understand this? According to Gregory, there are infinitely many overlapping parts, each of which is in some sense really there. And we can locate some of these parts by counting the parts that are obtained by dividing infinitely many times approaching one of the limits of the body, such that each part includes the limit of the body. If we do this, we will obtain infinitely many parts, each half the size of the previous one, and each one including the limit of the body. Thus each one of our infinitely many parts will be immediately adjacent to any body which touches the limits of the divided magnitude. So touching a body entails touching all of the infinitely many proportional parts that are obtained by dividing ever closer to the limit of a body. And this provides by analogy Gregory's solution to the adjacence problem. Each part of a magnitude is adjacent to infinitely many other parts.

There is something peculiarly elegant about Gregory's solution that the ultimate component parts of a magnitude must themselves be extended. In the last section of this paper, I will examine in further detail Gregory's response to Henry of Harclay. In order to understand both Gregory's own account and his response to Henry, however, we need to have some grasp of his account of the mathematics of infinity. It is to this that I now turn, taking as a starting point two objections which Gregory raises to his account of the composition of a magnitude.

\section{THE MATHEMATICS OF INFINITY}

Gregory, in typical scholastic fashion, offers a large number of objections to his position, at all places in the argument. Two of the most interesting run as follows. (1) If there are infinite parts in a magnitude, then either (i) there are no more parts in the whole than in any of the parts, or (ii) there are more parts in the whole than in any of the parts. But both are absurd. If (i), then, absurdly, the whole is not greater than its part; if (ii), then, absurdly, two infinites will be unequal.63 (2) If there are infinite parts in every magnitude, then there are as many parts in a grain of sand as there are in heaven. But this too seems absurd.64

In reply to the first of these Gregory refers his readers to a now well-known discussion of infinity found in book one of his Sentence commen-

62. S 2.2.2.1 (4:305, 11. 2-5). For the whole reply, see S $2.2 .2 .1(4: 304,1$. 29-305, 1. 8); see also S 2.2.2.1 (4:292, 11, 7-24).

63. S 2.2.2.1 (4:303, 11. 29-33).

64. S 2.2.2.1 (4:303, 11. 34-6). 
tary. In this discussion, Gregory attempts to distinguish different senses of 'greater' and 'lesser':

In one way [ greater and lesser] are taken properly, and thus a multitude . . . is called greater which contains "one" more times, or more unities, and indeed that [is called] lesser which [ contains "one"] fewer times, or fewer [ unities]. In another way it is taken improperly, and thus every multitude which includes all the unities of the other multitude and certain unities other than these is called greater than that, even though it does not include more [unities] than that. 65

When talking about magnitudes, and thus about infinitely many (extended) parts, 'greater' and 'lesser' apply in the second sense, but not in the first. 66 There are no more parts numerically in a whole magnitude than there are in a part of that magnitude: whole and part are equal in the sense that each part of the whole can be paired off with a part of the part. But the whole magnitude is greater than any of its parts in the sense that its parts are something like subsets of the whole: the whole includes more than any of its parts, "even though it does not include more unities than [any of its parts]."67

The answer to the second objection makes much the same point. Even though smaller magnitudes can be seen as subsets of larger ones, all magnitudes have the same "number" of parts, in the sense that the proportional parts of any magnitude can be paired off with the proportional parts of any other: "There are no more proportional parts in heaven than in a grain of sand." 68 Gregory's answer tries to flesh this out a bit, offering a theoretical explanation for the possibility of the set-subset relation that can exist between larger and smaller magnitudes. The elegant explanation Gregory offers ties in exactly with his insight that the infinitely many parts of a magnitude are themselves extended: heaven is larger than a grain of sand just because "parts of the same proportion in the two cases are not equally large, but [they are] larger in the larger [whole], and smaller in the smaller."69

65. S 1.42-4.4.2 ad $2(3: 458,11.27-33)$; the Latin text can also be found in Murdoch, "Infinity and Continuity," 572 n23.

66. S 1.42-4.4.2 ad 2 (3:458, 1. 35-459, 1. 1).

67. On this, see also Murdoch's discussion in "Infinity and Continuity," p. 572. Gregory's understanding of these matters is far more sophisticated than that of his close contemporaries: compare the relatively crude treatment of some of the same issues in, for example, Adam Wodeham, DI 5.1-3 (pp. 236-73). Wodeham argues that there are more proportional parts in larger magnitudes then in smaller magnitudes, even if the total number of parts in each is infinite.

68. S 2.2.2.1 (4:312, 11. 26-77).

69. S 2.2.2.1 (4:313, 11. 1-2; see also 4:312, 1. 7). 


\section{GREGORY ON HENRY OF HARCLAY}

While defending his claim that a magnitude cannot be composed of indivisibles, Gregor y considers three objections inspired by H enry of H arclay's account. 70 The point of all three objections is that each of the infinitely many parts of a continuum must be immediately adjacent to at least one other part and at most two other parts.

As $\mathrm{H}$ enry sees it, of course, the relevant parts are point-like indivisibles. So Gregory offers the following blanket reply to the arguments, referring us to the defense of non-entitism I discussed above: there are no such things as points at all, so a fortiori there are no points in a line.71 But, more interestingly, Gregory attempts to reply to the arguments individually, conceding for the sake of argument that there are such things as points. The gist of the replies is that, even if there are such things as points, such that infinitely many of them could compose a finite magnitude, we do not need to suppose that any of these points is next to another. (Gregory, of course, for the reason outlined in section one above, believes that the basic claim - that infinitely many points could compose a finite magnitude-is not only false but logically contradictory.) Gregory is able to use his understanding of infinity-derived from his own analysis of the composition of a continuum - to show that composition from points does not entail point adjacent to point. Thus, even though Gregory initially constructs his account of the infinite by presupposing that there are infinitely many overlapping parts, he sees that it can be used to talk, on a different analysis, about a division in which we actualize infinitely many points composing a magnitude. Gregory's insight, al ready discussed in section four above, is that if a continuum is composed of infinitely many parts, it is not necessary that every part is adjacent to at least one and at most two others.

The first two objections distinguish two of the themes implicit in Henry's "God sees all the points on a line" argument. The first argues that God sees point between point; the second that God sees a line between any pair of points. I give each objection, followed by Gregory's reply. (1) Either there is a midpoint $r$ between any two points $p$ and $q$ in a magnitude, or not. If there is, then either (i) $r$ is also the midpoint between itself and $p$, or (ii) $r$ does not belong to the same magnitude as $p$ and $q$. Both of these are absurd. If there is no midpoint between $p$ and $q$, then $p$ and $q$ are immediate to each other, which is Henry's claim. ${ }^{72}$ (The second dilemma [ (i) and (ii)

70. See S 2.2.2.1 (4:289, 1. 24-290, 1. 19); Gregory considers two other objections as well (S 2.2.2.1 [4:289, 11. 14-23; 290, 11. 20-36]); I do not discuss these more conventional arguments here.

71. S 2.2.2.1 (4:291, 11. 28-30). This reason does not account for Gregory's refusal to think of merely imaginary geometrical objects as composed of points; I get the impression that his opposition to indivisibilism is fairly deeply ingrained.

72. S 2.2.2.1 (4:289, 1.24-p .290, 1. 4). 
in the above argument] attempts to give an account of a midpoint $r$ supposing that there could not be a further midpoint between $p$ and $r$.) Gregory replies by noting that between any two points there is a third, while there is no one point between, for example, the first point and every other point on the line. Thus, there is no point adjacent to the first point. Furthermore, Gregory is happy to claim that God would see all of these points. 73 So I take it that Gregory has a conception of a magnitude as composed of actually infinitely many points ordered in such a way that between any two there is a third. 74

(2) God sees every point in a line. Either he sees that between any two points in the line there is an intermediate line, or he does not. If he does not, then he sees point immediate to point. If he does see the intermediate line, then he fails to see every point-supposing with Henry that seeing an intermediate line excludes seeing any further points. 75 Gregory replies that God sees a line intermediate between any two points:

I say that ... God sees that between the first point and any other of the same line a line intervenes, and [he sees] infinitely many points, and there is no line which is not seen, or point which is not seen by him. But God sees no line to inter vene between the first point and any other point seen by him. 76

So Gregory is clear that God does indeed see all the infinitely many points in a line, and any line which can inter vene between any pair of points. The last sentence of the quotation is prima facie puzzling. According to Henry, as we saw in section one, if there is a line between one point and the next, then there will be a point-the midpoint of the line- which God does not see. Gregory's claim in the last sentence is, I take it, that there is no line whose midpoint God cannot see.

(3) Suppose there is a point at the limit of a line. Either there is a further point between the limiting point and the line, or not. If there is, then the further point will be immediate to the limiting point. If there is not, then the first point will be immediate to all the other points on the line. 77 Gregory replies that there is no one point between the limit of a line and the line: however close to the limiting point we go, we can always go

73. S 2.2.2.1 (4:291, 1.33-p. 292, 1. 7).

74. Gregory thus accepts-counterfactually-that the infinitely many points in a continuum are what we would call densely ordered. ( $\mathrm{n}$ modern accounts of continuity, dense ordering is not sufficient for continuity. A set of continuously ordered points-unlike a set of densely ordered points-includes points corresponding to irrational numbers.) On this sort of conception, a line will be composed of parts-countably many parts - none of which is adjacent to another.

75. 5 2.2.2.1 (4:290, 11. 5-12).

76. S 2.2.2.1 (4:292, 11. 8-12).

77. S 2.2.2.1 (4:290, 11. 13-19). 
closer. This is, of course, exactly in line with the first two replies just considered.

The replies contrast interestingly with a similar one offered by the Aristotelian William of Alnwick.78 Alnwick argues in effect that God sees that between any two points there is a third; but that he cannot see every point which could possibly be located in this way. Alnwick's motivation here is presumably that, if God were to see all the points, he would have to see point adjacent to point-which is impossible on Alnwick's Aristotelian presuppositions. Gregory is happy for God to see that, between every pair of points, there is a third ("[there is no point] which is not seen by him"): so Gregory claims both that there are infinitely many points, and that there is no point which God does not see. Alnwick would thus deny what Gregory affirms: viz. that God sees the infinite totality of points on a line. Gregory's innovative claim is that the points do not need to be adjacent for God to see all of them. 79

Gregory's conception here is admissible only if he is prepared to allow that his account of the infinite is applicable not only to the number of levels of division, but also to the number of nonoverlapping (point-like) parts that exist-on a different account from his- at the end of a completed division. In fact, of course, the claim is in some ways quite different from Gregory's standard claim that each of the infinitely many parts of a continuum is immediately adjacent to infinitely many other such parts. On the proposed account of composition from point-like indivisibles, each of the infinitely many parts of a continuum is immediately adjacent to no other part. But Gregory, I think, feels entitled to this claim since he sees the way to denying the immediate adjacent claims made by all his opponents: namely, that if a continuum is composed of actually infinitely many pointlike indivisibles, then each will be adjacent to at least one and at most two other such indivisibles.

$* * *$

Gregory's analysis of the categorematically infinite represents a huge advance on that of his predecessors and contemporaries. He is the first thinker to provide a satisfactory theoretical rejection of Aristotle's account of composition from a potential infinity of parts, and the first thinker to

78. See his Det. 2 ( MS Vat. Palat. Lat. 1805, fol. 14r-v, quoted in Wood's edition of Adam Wodeham, DI, 292-93 n.4).

79. For a discussion of Alnwick's view, see John E. Murdoch, "Mathesis in Philosophiam Scholasticam Introducta: The Rise and Development of the Application of Mathematics in Fourteenth Century Philosophy and Theology," in Arts libéraux et philosophie au moyen âge: Actes du quatrième congrès in ternational de philosophie médiévale (Montreal: Institut d’Études Médiévales, 1969), p. 220. 


\section{RICHARD CROSS}

provide a clear solution to the paradoxes of inequality which seem to arise if we accept the infinitist conception of the composition of a continuum. Equally, he is the first to provide anything like an adequate account of the view that there are actually infinitely many component parts in a continuum. 80 Gregory is right to see-against both his Aristotelian opponents (Alnwick, Aureol, O ckham, and H ibernicus) and his non-A ristotelian opponent ( $\mathrm{H}$ enry of $\mathrm{H}$ arclay) - that the infinitely many parts of a continuum do not need to be such that each is immediately adjacent to at least one and at most two other parts.

Gregory's claim that the parts of an extended magnitude will themselves be extended is intellectually satisfying. As Aristotle spotted, if the parts are points, it is hard to see how extension could even, as it were, get off the ground. Gregory's account of infinite divisibility provides a way of allowing for composition from an actual infinity of extended parts.

80. As I noted above (n.51), Gregory is not alone in holding that a magnitude might contain infinitely many parts; but Gregory's position is that a magnitude is composed of infinitely many parts. 